\title{
Human Computer Interaction
}

\author{
Suvrunda Jadhav ${ }^{1}$, T.R.Patil ${ }^{2}$ \\ Student, IT Department, NBN Sinhgad School of Engineering, Pune. \\ Professor, IT Department, NBN Sinhgad School of Engineering, Pune.
}

\begin{abstract}
The intention of this paper is to provide an overview on the subject of Human-Computer Interaction. The overview includes the basic definitions and terminology, a survey of existing technologies and recent advances in the field, common architectures used in the design of HCI systems which includes unimodal and multimodal configurations, and finally the applications of HCI. This paper also offers a comprehensive number of references for each concept, method, and application in the HCI.
\end{abstract}

Keywords: Human-Computer Interaction, Multimodal HCI, Mobile Computing, Smart Environment, Science \& Technology.

\section{INTRODUCTION}

Utilizing computers had always begged the question of interfacing. The methods by which human has been interacting with computers has travelled a long way. The journey still continues and new designs of technologies and systems appear more and more every day and the research in this area has been growing very fast in the last few decades.

The growth in Human-Computer Interaction (HCI) field has not only been in quality of interaction, it has also experienced different branching in its history. Instead of designing regular interfaces, the different research branches have had different focus on the concepts of multimodality rather than unimodality, intelligent adaptive interfaces rather than command/action based ones, and finally active rather than passive interfaces.

This paper intends to provide an overview on the state of the art of HCI systems and cover most important branches as mentioned above. In the next section, basic definitions and terminology of HCI are given. Then an overview of existing technologies and also recent advances in the field is provided. This is followed up by a description on the different architectures of HCI designs. The final sections pertain to description on some of the applications of HCI and future directions in the field.

\section{HUMAN-COMPUTER INTERACTION: DEFINITION, TERMINOLOGY}

Sometimes called as Man-Machine Interaction or Interfacing, concept of Human-Computer Interaction/Interfacing (HCI) was automatically represented with the emerging of computer, or more generally machine, itself. The reason, in fact, is clear: most sophisticated machines are worthless unless they can be used properly by men. This basic argument simply presents the main terms that should be considered in the design of HCI: functionality and usability.

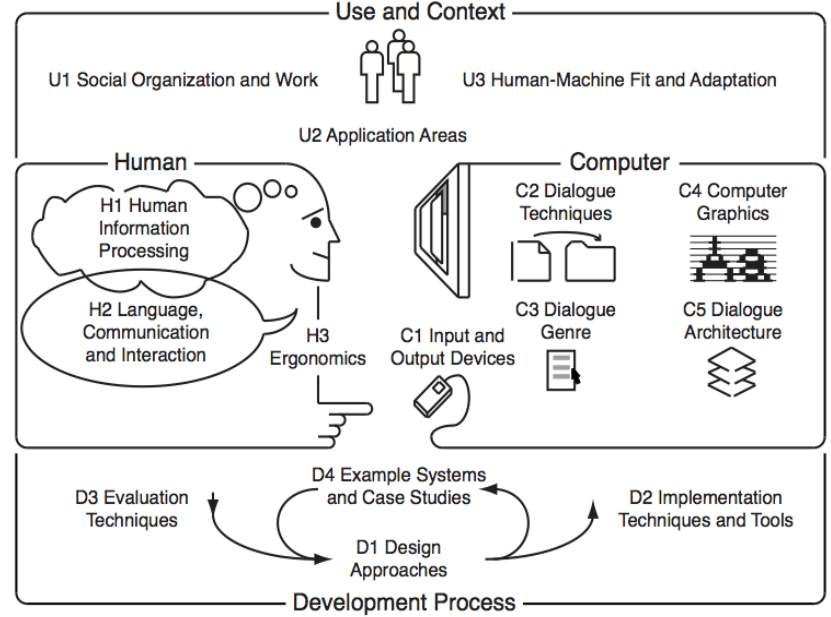

Figure. Human Computer Interaction

\section{EXISTING HCI TECHNOLOGIES}

HCI design should consider many aspects of human behaviours and needs to be useful. The complexity of the degree of the involvement of a human in interaction with a machine is sometimes invisible compared to the simplicity of the interaction method itself.

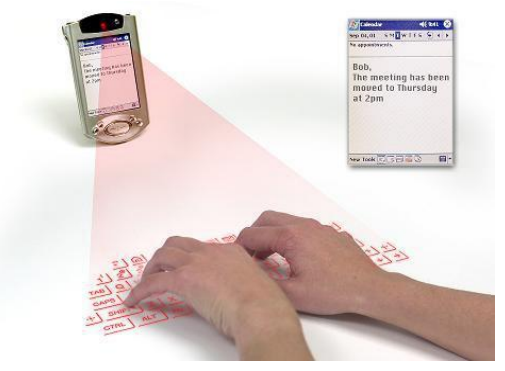

Figure. Virtual Keyboard

This is a virtual keyboard that is made by projecting a QWERTY like pattern on a solid surface using a red light. Then device tries to track user's finger movement while typing on the surface with a motion sensor and send the keystrokes back to the device. 


\section{HUMAN COMPUTER INTERACTION WITH SCIENCE}

Human-computer interaction (HCI) has had a long and troublesome relationship to the role of 'science'. HCI's status as an academic object in terms of coherence and adequacy is often in question-leading to desires for establishing a true scientific discipline. In this paper I explore formative cognitive science influences on HCI. Human-computer interaction (HCI) is represented by a large and growing research community concerned with the study and design of interactive technologies. It rapidly emerged from the research labs of the 1970s.

\section{HUMAN COMPUTER INTERACTION WITH SMART ENVIRONMENT}

Here, we provide an overview of the content of the Special Issue on "Human-computer interaction in smart environments". The aim of this Special Issue is to highlight technologies and solutions encompassing the use of mass-market sensors in current and emerging applications for interacting with Smart Environments. Selected papers address this topic by analyzing different interaction modalities, including hand/body gestures, face recognition, gaze/eye tracking, biosignal analysis, speech and activity recognition, and related issues.

\section{HCI SYSTEMS ARCHITECTURES}

Most important factor of a HCI design is its configuration. In fact, any given interface is generally defined by the number and diversity of inputs and outputs it provides. Architecture of a HCI system shows what these inputs and outputs are and how they work together. Following sections explain different configurations and designs upon which an interface is based. Based on the nature of different modalities, they can be divided into three categories:

1. Visual-Based
2. Audio-Based
3. Sensor-Based

\section{APPLICATIONS OF HCI}

- Smart Video Conferencing

- Intelligent Homes/Offices

- Driver Monitoring

- Intelligent Games

- E-Commerce

- Helping People with Disabilities

\section{LITERATURE SURVEY}

Virtual environments are envisioned as being systems that will enhance the communication between humans and computers. If virtual systems are to be effective and well received by their users, considerable human-factors research needs to be accomplished. This paper provides an overview of many of these human-factors issues, including human performance efficiency in virtual worlds (which is likely influenced by task characteristics, user characteristics, human sensory and motor physiology, multimodal interaction, and the potential need for new design metaphors); health and safety issues (of which cyber sickness and deleterious physiological after effects may pose the most concern); and the social impact of the technology. The challenges each of these factors present to the effective design of virtual environments and systematic approaches to the resolution of each of these issues are discussed

\section{ACKNOWLEDGMENT}

This work was partially supported by a grant from Intel Research Council. The authors gratefully acknowledge and thank David G. Novick and the anonymous reviewers for their helpful comments and suggestions.

\section{CONCLUSION}

Human-Computer Interaction is an important part of systems design. Quality of system depends on how it is represented and used by users. Therefore, enormous amount of attention has been paid to better designs of HCI. The new direction of research is to replace common regular methods of interaction with intelligent, adaptive, multimodal, natural methods.

Ambient intelligence or ubiquitous computing which is called the Third Wave is trying to embed the technology into the environment so to make it more natural and invisible at the same time. Virtual reality is also an advancing field of HCI which can be the common interface of the future. This paper attempted to give an overview on these issues and provide a survey of existing research through a comprehensive reference list.

\section{REFERENCES}

[1] D. Te'eni, J. Carey and P. Zhang, Human Computer Interaction: Developing Effective Organizational Information Systems, John Wiley \& Sons, Hoboken (2007).

[2] B. Shneiderman and C. Plaisant, Designing the User Interface: Strategies for Effective Human-Computer Interaction (4th edition), Pearson/Addison-Wesley, Boston (2004).

[3] J. Nielsen, Usability Engineering, Morgan Kaufman, San Francisco (1994).

[4] D. Te'eni, "Designs that fit: an overview of fit conceptualization in HCI", in P. Zhang and D. Galletta (eds), Human-Computer Interaction and Management Information Systems: Foundations, M.E. Sharpe, Armonk (2006).

[5] A. Chapanis, Man Machine Engineering, Wadsworth, Belmont (1965).

[6] D. Norman, "Cognitive Engineering”, in D. Norman and S. Draper (eds), User Centered Design: New Perspective on HumanComputer Interaction, Lawrence Erlbaum, Hillsdale (1986).

[7] R.W. Picard, Affective Computing, MIT Press, Cambridge (1997).

[8] J.S. Greenstein, "Pointing devices", in M.G. Helander, T.K. Landauer and P. Prabhu (eds), Handbook of Human-Computer Interaction, Elsevier Science, Amsterdam (1997).

[9] B.A. Myers, "A brief history of human-computer interaction technology”, ACM interactions, 5(2), pp 44-54 (1998).

[10] B. Shneiderman, Designing the User Interface: Strategies for Effective Human-Computer Interaction (3rd edition), Addison Wesley Longman, Reading (1998). 